\title{
Time to register for the World Congress of Gastroenterology meeting in Montreal: September 10-14, 2005
}

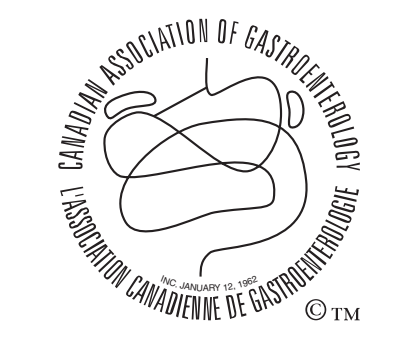

En français voir page 473

En francais voir page 473

\author{
Philip M Sherman MD FRCPC \\ Vice-President, Canadian Organizing Committee, Past-President, Canadian Association of \\ Gastroenterology
}

Richard N Fedorak MD FRCPC

President, Canadian Organizing Committee

Desmond Leddin, MB FRCPC

President, CAG
$\mathrm{B}$ y now, you should have received an announcement regarding the World Congress of Gastroenterolgy (WCOG) 2005 meeting in Montreal, Quebec entitled "Global Goals in Gastroenterology - Expanding Horizons in the 21st Century". Enclosed with the announcement is a registration form. We have completed and sent in our forms already - and now encourage you to do the same!

The registration includes a novel and innovative program that presents a number of new and exciting initiatives. For example, Norm Marcon and his colleagues have kindly agreed to present their annual endoscopy course as part of the WCOG 2005 program. As a result, there will be live endoscopy each day of the meeting with commentary from experts in Canada and from around the world. This experience alone makes registration worthwhile and meaningful to all Canadian physicians and surgeons active in the practice of gastroenterology and hepatobiliary medicine.

This world-class program is currently being finalized and will include global perspectives in colon cancer, host-microbe interactions (enteric infections) and functional bowel disorders, including current understanding of and novel interventions to interrupt visceral pain. These bench-to-bedside presentations will highlight evidence-based approaches, where applicable. Concurrent hepatology and surgical programs will ensure that there is something of interest for everyone throughout the duration of the meeting. There will be multiple presentations relevant to pediatric gastroenterologists, including a state-of-the-art Lectureship named in honour of the late Dr Hinda Kopelman.

The social program includes an opening ceremony and welcoming reception on the evening of Sunday, September 11 and a Canada Night celebration on Tuesday, September 13. There are also available, for spouses and accompanying persons, a number of tours and excursions that will be of interest to both Canadians and our guests from abroad. We trust that you will join us in presenting Canada and the Canadian gastroenterology community in the best possible manner to friends and colleagues from around the world. Based upon initial feedback, we are confident that attendance at the meeting will be excellent.

A series of eight postgraduate courses also will take place either before or after the WCOG 2005 meeting. One receives a $15 \%$ discount from WCOG 2005 Congress registration fee when attending both the core program and a postgraduate course. Early registration will end on December 31, 2004, with an increase in fees after this time. Additional information is available, for your consideration, at <www.wcog2005.org >. In addition, please do not hesitate to contact either of us directly with your comments, questions and feedback.

The Canadian Association of Gastroenterology (CAG) is planning to host a small meeting in Montreal, which will run outside the core WCOG 2005 program and will cover topics that will not be duplicated at the WCOG 2005 meeting. The current plan is to develop the CAG program around issues of access and resources for gastroenterology in Canada. A focus on advances in the basic sciences and inflammatory bowel diseases and the Annual General Business meeting of the CAG will also take place on the weekend in advance of the WCOG 2005.

We are very much looking forward to sharing with you the excitement of hosting the WCOG 2005 in Montreal and trust that you will register soon for this opportunity. 


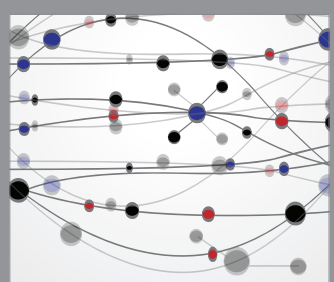

The Scientific World Journal
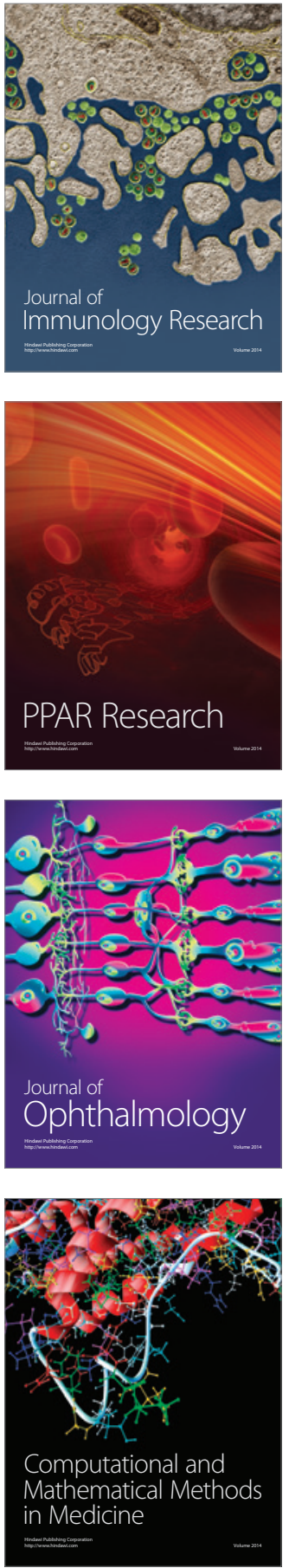

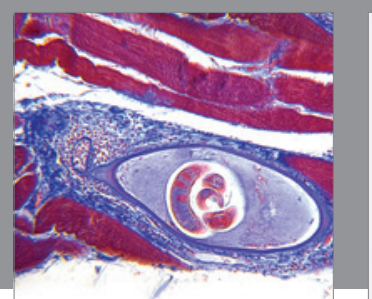

Gastroenterology Research and Practice

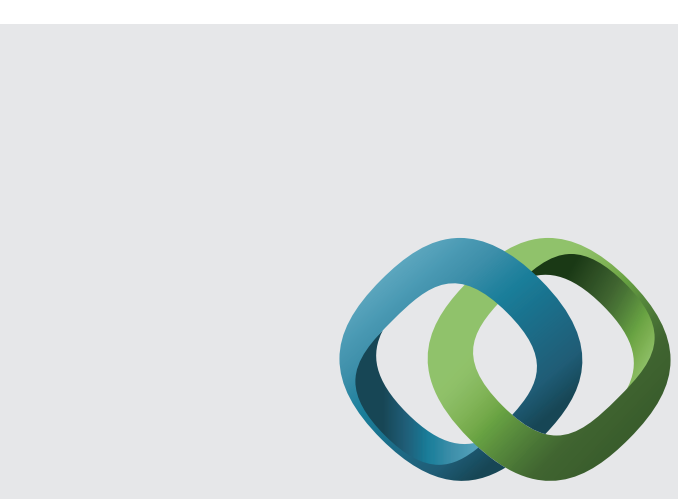

\section{Hindawi}

Submit your manuscripts at

http://www.hindawi.com
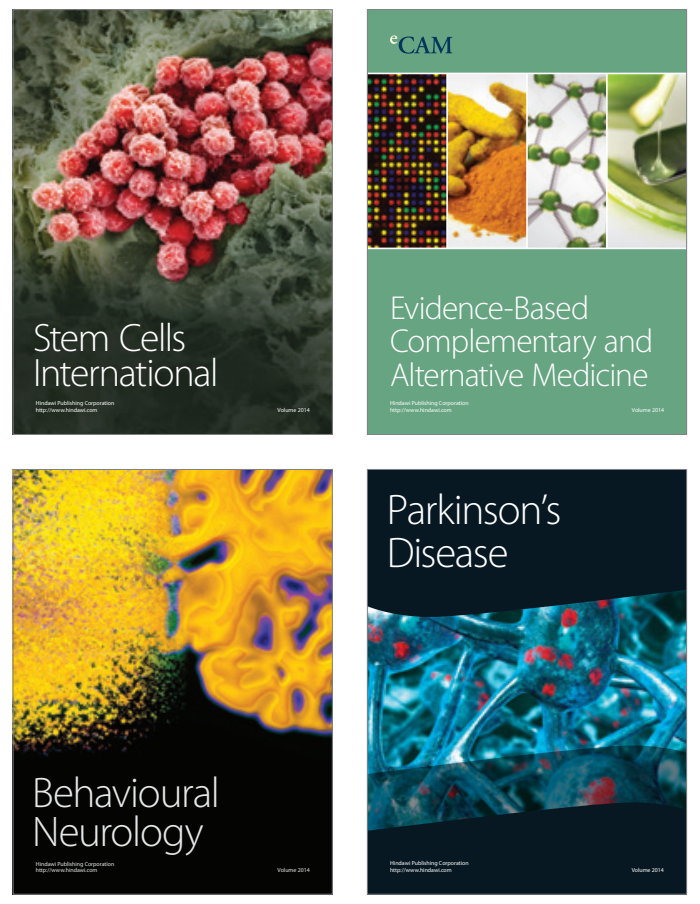
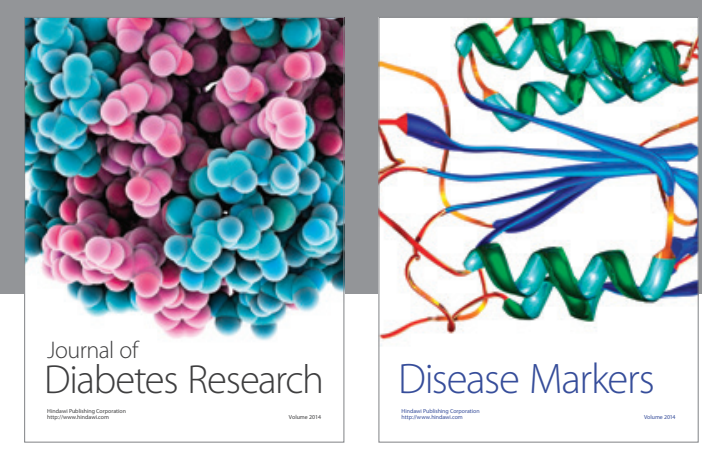

Disease Markers
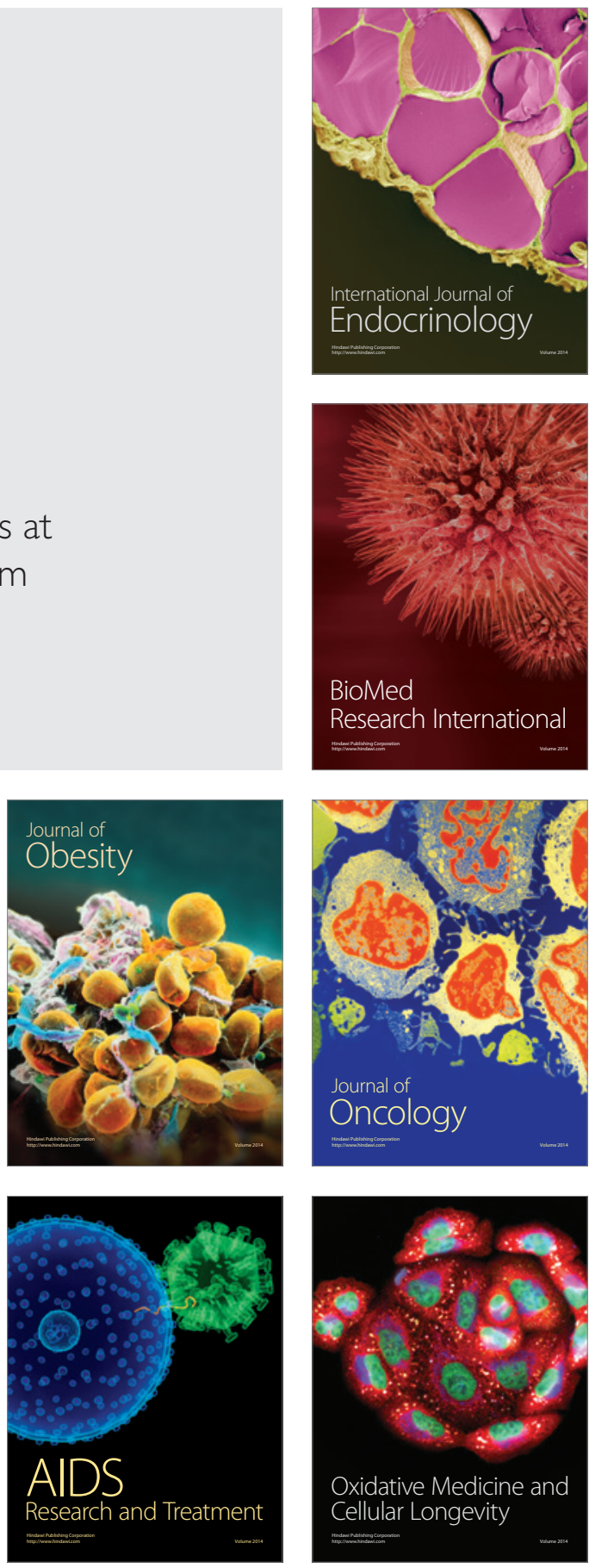